\title{
The effect of a commercial probiotic product on the milk quality of dairy cows
}

\author{
T. W. J. Olchowy, ${ }^{1}$ M. Soust, ${ }^{2}$ and J. Alawneh ${ }^{1 *}$ \\ ${ }^{1}$ Good Clinical Practice Research Centre, The University of Queensland, School of Veterinary Science, Gatton, Queensland 4343, Australia \\ ${ }^{2}$ Terragen Biotech Pty Ltd., Coolum Beach, Queensland 4573, Australia
}

\section{ABSTRACT}

Probiotics intended to improve plant health and productivity of pastures grazed by dairy cow are becoming commercially available in Australia. Great Land (GL; Terragen Biotech Pty Ltd., Coolum Beach, QLD, Australia) is one such biologic soil conditioner and spray-on probiotic with a label claim of "acting to improve plant health and productivity." The objective of this study was to quantify the effect of GL on the milk quality of cows grazing pasture top-dressed with GL. Lactating dairy cows of mixed age and breed (primarily HolsteinFriesian), in their second lactation or greater, and at least $80 \mathrm{~d}$ in milk were enrolled and randomly allocated into 1 of 2 study groups: a treatment cow group $(\mathrm{n}=$ 98; cows grazed pasture that was top-dressed with GL according to the product label) and a control cow group ( $\mathrm{n}=114$; cows grazed untreated pasture). As required, both groups were supplemented at the same rate with a mixed ration during the grazing period. Composite milk samples were collected weekly from each cow during the study and analyzed to determine milk components. Milk volumes were recorded at each milking using the herd management software of the study farm. Mean differences in the milk component variables were compared using mixed-effects linear regression models. After controlling for the effect of days in milk, cow lactation, and time since a cow entered the study, the treatment cows produced an average of $1.21 \mathrm{~L} /$ cow per day more milk (95\% confidence interval: $0.34-2.08 \mathrm{~L} /$ cow per day) and more milk protein $(0.03 \mathrm{~kg} / \mathrm{d} ; 95 \%$ confidence interval: $0.01-0.05 \mathrm{~kg} / \mathrm{d}$ ) than the control cows. Pasture cover and pasture consumption did not differ between the GL-treated and the untreated study paddocks grazed by the treatment or control cows. A limited amount of published data have examined the effect of probiotic pasture treatment on the milk quality of dairy cows. This study suggests that application of such products may be beneficial. The mechanisms

Received July 19, 2018.

Accepted November 19, 2018.

*Corresponding author: j.alawneh@uq.edu.au associated with this type of outcome remain to be investigated.

Key words: probiotics, milk quality, dairy cattle, pasture

\section{INTRODUCTION}

Pasture-based dairy production systems are very common in Australia and New Zealand. The relatively inexpensive input cost of local forage, compared with a TMR, facilitates the economic production of milk (Dillon et al., 2005; Doyle and Stockdale, 2011; Stergiadis et al., 2015). As a consequence, options for pasture management that improves feed production at an acceptable multiple of the input cost should improve the economic viability of a commercial dairy operation (Mulliniks et al., 2015). However, the opportunity to maximize milk production in a pasture-based dairy system may be restricted if the forage nutrient supply is limited or as a consequence of seasonal variations in the nutrient value of the plant species (Chapman et al., 2008). This is further complicated by the genetic changes of the dairy cow, which have resulted in increased milk production on a per-cow basis (Fike et al., 2003). These genetic changes are not uniform across the Holstein-Friesian breed, with certain genetic groups being more or less suitable to a pasture-based dairy production system (Macdonald et al., 2008). In a pasture-based system, the intake of nutrients by a dairy cow, on either a per-mouthful or per-step basis, may have a significant effect on the daily production per cow and therefore on the overall economic state of the dairy property.

The growth or the quality of the pasture may be improved by selecting appropriate pasture plants for the expected climatic conditions, soil testing and correction of deficiencies by application of specific fertilizers and other plant nutrients, and use (if available) of irrigation (Waghorn and Clark, 2004; Hopkins and Wilkins, 2006; Ferris, 2007). Correctly managed, higher quality pasture forage should provide the basis for increased milk production or improved milk composition (Shalloo et al., 2011; Hanrahan et al., 2018). From the cow's per- 
spective, probiotics and prebiotics have been administered to cows for several years to enhance animal health and production. Recently, the use of a pasture-applied biological has shown some promise of improving milk quality and milk production.

Great Land (GL; Terragen Biotech Pty Ltd., Coolum Beach, QLD, Australia) is a commercial spray-on probiotic with a label claim of acting to improve plant health and productivity. It is currently used on several Australian dairy properties and has anecdotally been associated with a substantial improvement in milk quality. The objective of this study was to quantify any effect GL may have on the milk quality of cows grazing pasture top-dressed with this probiotic.

\section{MATERIALS AND METHODS}

\section{Study Location and Animals}

This study was conducted between May 30 and December 4, 2016, on a commercial dairy property in Southeastern Queensland, Australia. The milking herd consisted of approximately 280 dairy cows from which the study cows were selected (Table 1). All cows in the study had free access to both water and their allocated pasture. Typical of Southeastern Queensland dairy production systems, the study cows were managed as 2 separate groups such that the pasture allowance (3-6 $\mathrm{kg}$ of $\mathrm{DM} / \mathrm{cow}$ per day) and the mixed feed (partial mixed ration) supplement (provided as needed after the morning milking) were sufficient for the maintenance and production requirements of a $650-\mathrm{kg}$ cow producing $37 \mathrm{~L}$ of milk/d. The mixed ration was formulated with the following ingredients (given in $\mathrm{kg}$ of $\mathrm{DM} / \mathrm{cow}$ per day): barley grain, 2.64; wheat grain, 2.05; canola meal, 2.73; lucerne (alfalfa) hay, 2.13; and maize silage, 8.50. The mixed ration was provided in separate feed troughs located on the feed pads of each study group. The pasture consisted of an 80:20 mix of ryegrass (Lolium perenne) and white clover (Trifolium repens). The chemical analysis of the total ration is reported in Table 2. The study was preapproved by the University of Queensland's Research and Innovation Animal Welfare Committee before the start of any study activities (UQ-AEC no. SVS/538/15/TERRAGEN).

\section{Study Cow Group Size and Enrollment Criteria}

The number of cows required to test the mean differences in milk quality components (milk volume, fat, and protein) was based on SCC. This milk component was expected to have the largest degree of variability. This ensured that there was a sufficient number of cows to test for significant differences within the remaining

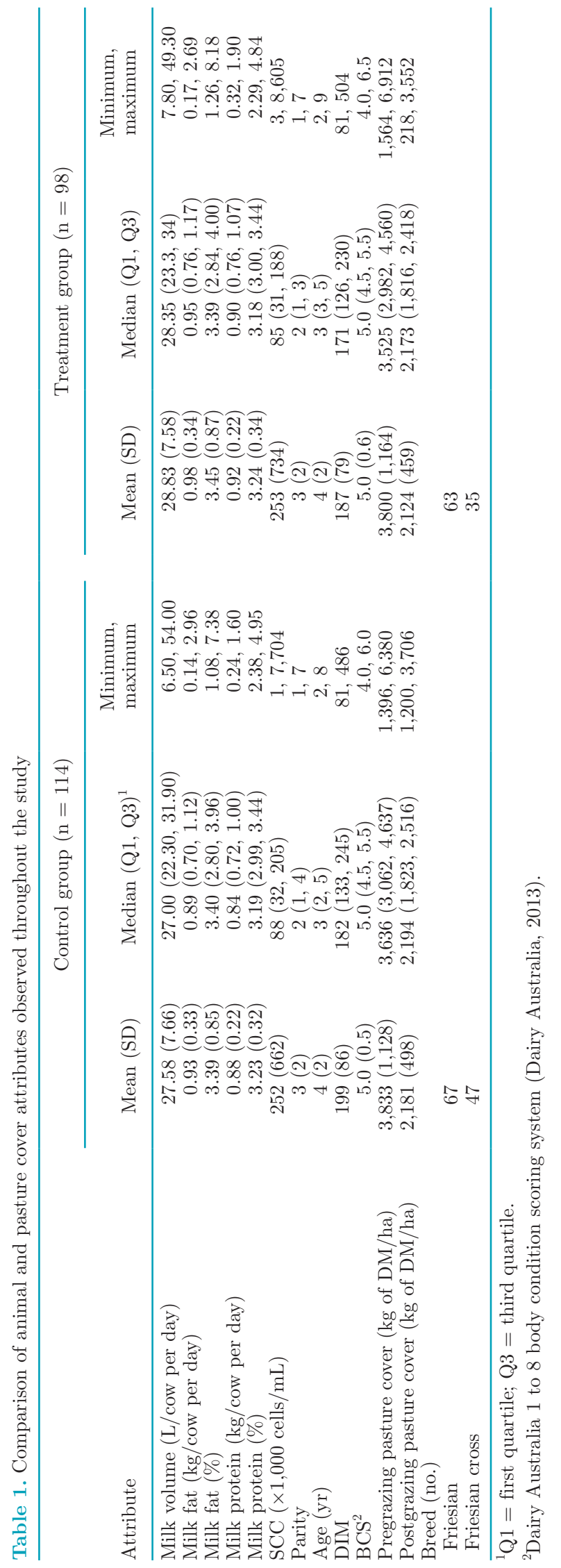

Journal of Dairy Science Vol. 102 No. 3, 2019 
milk components. The a priori study assumptions used to determine the sample size (number of cows) were as follows: both groups were balanced, both groups had a similar between-groups variance, the variance observed due to GL application was $30 \%$ of the overall variance, an effect size of $5 \%$, a power of $80 \%$, and a significance level of $95 \%$. Based on these assumptions, the minimum total sample size was determined to be 188 cows. A total of 212 clinically healthy milking dairy cows that had passed 80 DIM and had an individual cow SCC of $<300,000$ cells $/ \mathrm{mL}$ in the most recent milk quality test were enrolled in the study.

\section{Milking and Milk Quality Data}

All cows were milked twice daily in the same milking parlor facility by the same milking staff and following the same milking procedures as the rest of the commercial dairy herd. Cows in the same treatment groups were milked together. On-farm milk sampling meters (GEA Westfalia, VIC, Australia) were used to collect individual cow composite milk samples. Milk samples were placed into vials containing a milk preservative and shipped to a commercial milk analysis laboratory (Dairy Express Herd Recording Service, University of New England, Armidale, NSW, Australia), which determined the milk fat percentage, milk protein percentage, and SCC. Individual cow daily milk production volumes were obtained from the study farm's dairy herd management software program (GEA Westfalia).

\section{Pasture Management}

The study farm had 11 well-defined grazing paddocks established before the start of the study. All paddocks were similarly managed with regards to grazing time, rotation frequency, and the irrigation program. Each of these 11 paddocks was subdivided along its length

Table 2. Chemical analysis (\% of DM unless noted) of the total ration used in this study

\begin{tabular}{lc}
\hline Item & Value \\
\hline DM (\%) & 30.55 \\
CP & 16.17 \\
ADF & 23.18 \\
NDF & 37.48 \\
NFC & 37.06 \\
Lignin & 2.75 \\
Starch & 24.91 \\
Fat & 2.67 \\
Calcium & 0.71 \\
Phosphorus & 0.44 \\
Selenium & 0.45 \\
\hline
\end{tabular}

to create 22 paired grazing subpaddocks, each approximately 1.5 ha in size. The paired subpaddocks were grazed for approximately $2 \mathrm{~d}$, and then the cows moved to the next pair of subpaddocks according to the grazing rotation program. If required, the grazing period on any pair of subpaddocks was adjusted based on the consumption pattern of the cows. Rainfall gauges were placed in the grazing paddocks to ensure consistency of water application (natural rainfall, irrigation) across the paired subpaddocks. To facilitate animal movements to and from the milking parlor, color-coded posts were placed at the entrances and exits of the subpaddocks to match the cow groups (each group had a matching colored ear tag).

\section{GL Storage and Application to Pasture}

Great Land is a liquid product containing a mixture of multispecies, multistrain bacteria and yeast of environmental origin: Lactobacillus spp. (L. parafarraginis, L. buchneri, L. rapi, L. zeae; minimum concentration of each strain was $\left.10^{6} \mathrm{cfu} / \mathrm{mL}\right)$, Acetobacter fabarum (minimum concentration of $10^{5} \mathrm{cfu} / \mathrm{mL}$ ), and Candida ethanolica (minimum concentration of $10^{6} \mathrm{cfu} / \mathrm{mL}$ ). The product was produced as a concentrate to be diluted just before use, and for this study, the product was stored at ambient temperature in a shaded area per the manufacturer's recommendations. Great Land was applied according to manufacturer's directions (40 $\mathrm{L}$ of GL/ha as a $10 \%$ solution in water) immediately before the start of the study and twice more during the study at approximately equal intervals. The application was made using a commercial tractor-mounted sprayer. Before the start of the study, several test spray runs using water were applied to subpaddocks to verify the tractor travel speed that would apply an even distribution of the fluid volume over the entire spray area. To ensure no carryover of GL residue between spray applications, the spray tank was cleaned before and after each application of the GL. A mock application (no spray applied) was made on the untreated paired subpaddock to create tractor tire tracks that mimicked those on the GL-treated paddock and maintained the study blinding.

\section{Pasture Measurements}

Pasture cover was determined immediately before (pregrazing pasture cover) and immediately after (postgrazing pasture cover) each grazing event using a commercial pasture meter (Folding Plate Pasture Meter, model EC-09; Jenquip, Feilding, New Zealand). Briefly, individual pastures were walked diagonally from corner 
to corner and approximately 15 measurements were made at equally spaced distances along each diagonal. Pasture consumption was defined as the difference in the pre- and postgrazing pasture cover.

\section{Randomization of Treatments to Paddocks}

This was a blinded, controlled, randomized block design study. The blocking factor was the application of GL to the subpaddocks. Before the start of the study, a paddock was randomly selected (from paddocks 1 to 11) and then one of the subpaddocks (A or B) of that specific paddock was assigned to spray treatment with GL using a simple random sampling method. Thereafter, the systematic assignment of treatment (sprayed with GL) to a specific member of the subpaddock pair (11 pairs) was based on the proximity of the subpaddock to the first randomly selected subpaddock. In brief, the subpaddock immediately adjacent to the first subpaddock assigned to the GL treatment (back-to-back location) was assigned to receive the GL treatment. The other subpaddock of this pair, which was located farthest from the initial subpaddock assigned to the GL treatment, became the untreated control subpaddock of the new pair. This GL treatment assignment pattern minimized the risk of potential cross-contamination between paddocks associated with the spray application of GL.

\section{Animal Assignment to Study Group}

Probability sampling was used to allocate individual cows into 1 of the 2 study groups: the GL-treated group (TG) and the untreated control group (CG). Each animal in each group received a colored ear tag unique to that group to facilitate animal movements to and from the milking parlor and the grazing paddocks. The 2 groups were balanced with respect to lactation number, BCS, and stage of lactation (Supplemental Table S1, https://doi.org/10.3168/jds.2018-15411). A 1-way ANOVA was used to assess the homogeneity of group means for lactation number, BCS, and stage of lactation.

\section{Pasture and Milk Data Management}

Each of the 621 pasture measurement records from the 11 paddocks was regarded as a single unique observation within the study period. A pasture measurement record included study week of pasture measurement, calendar date, pregrazing pasture cover $(\mathrm{kg}$ of $\mathrm{DM} / \mathrm{ha})$, postgrazing pasture cover ( $\mathrm{kg}$ of $\mathrm{DM} / \mathrm{ha})$, percentage of pasture consumption (calculated value), and study group (TG or CG).

The 3,421 weekly milk component analysis records from the 212 study cows were also regarded as single unique observations, with each observation including the details pertaining to an individual cow: identity, weekly milk component measurements, lactation number, breed, milk component measurement before the study, DIM, and study group (TG or CG). Somatic cell count values were $\log _{10}$ transformed to stabilize the SCC variance and allow statistical modeling and hypothesis testing.

\section{Statistical Analysis}

Pasture Measurements. Two separate mixed linear models that included a random intercept and slope term for each paddock were used to estimate the effect of GL on the mean pregrazing pasture cover and pasture consumption over the study period. Models were built using a forward modeling procedure with study group fitted as a fixed effect, paddocks fitted as random intercept, and study week (calendar week since the start of the study) fitted as random slope. The structure of the pregrazing model was as follows (the pasture consumption model had similar structure but with pregrazing pasture cover fitted as a covariate):

$$
\begin{aligned}
y_{i k} & =\beta_{0}+\beta_{1} t_{i}+\beta_{2} t_{i}^{2}+\text { group }_{j}+\text { t.group }_{i j}+t^{2} \text {.group }_{i j} \\
& +\alpha_{0 k}+\alpha_{1 k} t_{i}+\alpha_{2 k} t_{i}^{2}+\varepsilon_{i k},
\end{aligned}
$$

where $y_{i k}$ is the $i$ th weekly (study week $t$ ) pregrazing pasture cover measured on paddock $k, \beta_{0}$ is a regression coefficient for the intercept, and $\beta_{1}$ and $\beta_{2}$ are regression coefficients for the second-order polynomial terms to estimate weekly pregrazing pasture cover as a function of calendar week across all paddocks. The terms group $_{j}$, t.group $_{i j}$, and $t^{2}$.group $i j$ represent fixed effects of study group $j$ and second-order polynomial terms interaction with study group $j$ on $y_{i k}$, respectively. The random intercept $\left(\alpha_{0 k}\right)$ and random slope terms $\left(\alpha_{1 k}\right.$ and $\alpha_{2 k}$ ) describe the deviation of paddocks $k$ 's pregrazing weekly pasture cover measurements from that of the rest of the paddocks, and $\varepsilon_{i k}$ represents the random residual error.

Milk Components Measurements. A mixed linear model that included a random intercept and slope term for each cow and paddock (cow-paddock) was used (Tempelman, 2004; Bello et al., 2016) to estimate the effect of study group membership on average milk fat $(\mathrm{kg} / \mathrm{d})$, milk protein $(\mathrm{kg} / \mathrm{d})$, individual cow $\mathrm{SCC}$, 
and milk volume $(\mathrm{L} / \mathrm{d})$ over the duration of the study. A forward modeling procedure was used to build a separate mixed-effects model for each milk component, with study group fitted as a fixed effect, cow fitted as random intercept, and study week fitted as random slope. The structure of the models was as follows:

$$
\begin{aligned}
y_{\text {inp }} & =\beta_{0}+\beta_{1} t_{i}+\text { DIM }_{j}+\text { lactation }_{k}+\text { AveFeedIn }_{l} \\
& + \text { group }_{m}+\text { AveFeedIn.group }_{l m}+\text { t.group }_{i m}+\alpha_{0 p} \\
& +r_{0 n}+\alpha r_{1 p n} t_{i}+\varepsilon_{i p n},
\end{aligned}
$$

where $\mathrm{y}_{\text {inp }}$ is the $i$ th weekly (study week $t$ ) milk component measured on cow $n$ from paddock $p, \beta_{0}$ is a regression coefficient for the intercept, and $\beta_{1}$ is a regression coefficient to estimate weekly milk component as a function of study week across all cows. The terms DIM $_{j}$, lactation $k$, AveFeedIn , group $_{m}$, AveFeedIn.grou$p_{l m}$, and t.group $p_{i m}$ represent the fixed effects of DIM, lactation, average DM feed intake, study group, firstorder interaction between average DM feed intake and study group, and study week and study group on $y_{\text {inp }}$, respectively. The random intercepts $\left(\alpha_{0 p}\right.$ and $\left.r_{0 n}\right)$ and random slope term $\left(\alpha r_{1 p n}\right)$ describe the deviation of cow $n$ 's weekly milk component measurement on paddock $p$ from that of the rest of the cows grazing the same paddock, and $\varepsilon_{i p n}$ represents the random residual error.

For all models described above, residuals errors were assumed to follow a first-order autoregressive correlation pattern for weekly milk component measurements within each cow (Diggle, 2002). If polynomial terms were used in the model, the order of the polynomial terms was based on the model's Akaike information criterion. Raw and normalized residuals were evaluated graphically against predicted values to test the assump- tion of homogeneity of variance of the error terms. The mixed models were fitted using the restricted maximum likelihood procedure in the nlme package (Pinheiro et al., 2008) in R (R Development Core Team, 2010).

\section{RESULTS}

\section{Pasture Measurements}

There was no significant difference in pregrazing pasture cover, postgrazing pasture cover, or the resulting calculated pasture consumption between the 2 study groups (Supplemental Figure S1, https://doi.org/10 $.3168 /$ jds.2018-15411).

\section{Milk Component and Animal Measurements}

Milk volume and milk protein production were greater in the cows grazing the GL-treated paddocks (Tables 3 and 4). After controlling for the effect of DIM, lactation number, estimated DMI, and time since the cow entered the study, the mean daily milk production of cows in the TG group was approximately $1.21 \mathrm{~L} / \mathrm{d}(95 \%$ CI: $0.34-2.08 \mathrm{~L} / \mathrm{d}, P<0.01)$ greater than that of the CG cows. Cows in the TG group produced more milk protein $(0.03 \mathrm{~kg} / \mathrm{d} ; 95 \%$ CI: $0.01-0.05 \mathrm{~kg} / \mathrm{d}, P=0.01)$ and had a tendency toward greater production in milk fat $(0.02 \mathrm{~kg} / \mathrm{d} ; 95 \%$ CI: -0.03 to $0.05 \mathrm{~kg} / \mathrm{d}, P=0.32)$ compared with the CG cows (Supplemental Figure S2, https://doi.org/10.3168/jds.2018-15411). The response of the individual cow SCC to grazing GL-treated and untreated pasture was variable and not significantly different between the 2 groups (Supplemental Figure S3, https://doi.org/10.3168/jds.2018-15411).

\begin{tabular}{|c|c|c|c|}
\hline Variable & Coefficient (SE) & $95 \% \mathrm{CI}$ & $P$-value ${ }^{2}$ \\
\hline Intercept & $24.60(0.57)$ & 23.48 to 25.71 & $<0.01$ \\
\hline DIM & $-0.04(0.01)$ & -0.05 to -0.03 & $<0.01$ \\
\hline \multicolumn{4}{|l|}{ Lactation } \\
\hline First and second & Referent & & \\
\hline Third or greater & $5.21(0.38)$ & 4.47 to 5.96 & $<0.01$ \\
\hline Study week & $0.06(0.05)$ & -0.04 to 0.15 & 0.76 \\
\hline Average feed intake (DM/cow) & $0.03(0.03)$ & -0.02 to 0.08 & 0.41 \\
\hline \multicolumn{4}{|l|}{ Study group } \\
\hline Control & Referent & & \\
\hline Treatment & $1.21(0.44)$ & 0.34 to 2.08 & $<0.01$ \\
\hline \multicolumn{4}{|l|}{ Study week $\times$ study group } \\
\hline Control & Referent & & \\
\hline Treatment & $-0.01(0.03)$ & -0.06 to 0.04 & 0.58 \\
\hline
\end{tabular}

Table 3. Coefficients and SE from a mixed-effects regression model ${ }^{1}$ of weekly average milk volume (L) during the study period

${ }^{1}$ Model was fitted with cow and paddock as random effect with random intercepts. Study weeks were fitted as random slope with an autoregressive correlation structure for the residuals.

${ }^{2}$ Likelihood ratio test of the variable's effect on model fit. 
All enrolled cows completed the study. There were no differences between the groups with regards to the incidence risk of mastitis (risk ratio $=1.20,95 \%$ CI: $0.80-1.80, P=0.45$ ), lameness (risk ratio $=0.90,95 \%$ CI: $0.20-3.60, P=0.85$ ), metabolic disorder (recumbent or weak; risk ratio $=0.20,95 \%$ CI: $0.00-1.90, P=$ 0.13 ), gastrointestinal disorder (left displaced abomasum; $P=0.13$ ), or respiratory disease (pneumonia; $P=$ 0.28; Supplemental Table S2, https://doi.org/10.3168/ jds.2018-15411).

\section{DISCUSSION}

Forage consumed directly from grazing paddocks is a critical component of the nutritional management of dairy cows in Australia and New Zealand. As such, this dietary component can be the limiting factor in production of both milk volume and milk components (Stergiadis et al., 2015; Hanrahan et al., 2018). In this study we investigated the effect of a probiotic (GL) applied to the pasture rather than the cow. Producers have used this product for some time, but to our knowledge, this is the first comparative study of the potential beneficial effects of such a product.

The study demonstrated differences in production and milk quality as a result of GL application to grazing paddocks. Milk production volume and milk protein were greater on a per-cow per-day basis in the TG cows than in the CG cows. There was a tendency toward greater milk fat production in the TG cows. The demographic equivalence of the 2 cow groups makes it unlikely that the observed production differences were related to animal allocation. All cows were subjected to the same environmental conditions, grazed equal amounts of ryegrass pasture on adjacent paddocks, and were milked in the same manner. It is therefore probable that the observed differences were due to an effect on pasture quality.

Postgrazing pasture cover volume suggests that access to adequate feed was not a factor limiting production in the CG cows. Concurrent grazing of adjacent subpaddocks by the study cows should have minimized any variation in soil types between the 1.5-ha plots and eliminated soil composition as a factor contributing to the observed differences. Standardization of farm practices and use of milking facilities should have minimized any paddock location or effect due to group assignment of individual cows. Any supplemental feed offered was mixed in 1 batch using a commercial mixer wagon and provided at the same rate per head to both groups. A single source of water was used to fill the drinking water tanks for both groups. The feed pad was of identical construction (footing, bunk type, available linear bunk space per cow, waterer type) and provided the same amount of shade cover to each group. The grazing pressure of each subpaddock (cows per hectare) was approximately the same for both groups, suggesting that there was equivalent pasture consumption by individual cows and that variation in feed intake was not responsible for the production differences. The roles of paddock-to-paddock variations in soil nutrient content and bioavailability, plant nutrient content, and potential transfer of nutrients along drainage patterns were not investigated.

The study had several potential limitations associated with the pasture measurements. The determination of pasture growth and consumption was limited to an estimate of group DMI based on plate meter measure-

Table 4. Coefficients and SE from a mixed-effects regression model $^{1}$ of weekly average milk protein $(\mathrm{kg})$ during the study period

\begin{tabular}{lccc}
\hline Variable & Coefficient (SE) & $95 \%$ CI & $P$-value \\
\hline Intercept & $0.81(0.02)$ & 0.78 to 0.84 & $<0.01$ \\
DIM $^{3}$ & $-0.08(0.01)$ & -0.09 to -0.07 & $<0.01$ \\
Lactation & Referent & & \\
$\quad$ First and second & $0.17(0.01)$ & 0.15 to 0.18 & $<0.01$ \\
$\quad$ Third or greater & $-0.08(0.12)$ & -0.50 to 0.10 & 0.47 \\
Study week & Referent & & \\
Study group & $0.03(0.01)$ & & 0.01 to 0.05 \\
$\quad$ Control & Referent & -0.19 to 0.11 & \\
$\quad$ Treatment & $-0.04(0.08)$ & 0.60 \\
$\quad$ Study week $\times$ study group & 3 \\
$\quad$ Treatment & Treatment &
\end{tabular}

${ }^{1}$ Model was fitted with cow and paddock as random effect with random intercepts. Study weeks were fitted as random slope with an autoregressive correlation structure for the residuals.

${ }^{2} P$-values were derived from likelihood ratio test of the variable's effect on model fit.

${ }^{3}$ Coefficient multiplied by $10^{2}$. 
ments. Additional comparisons that may have helped elucidate the underlying reason for milk production differences would have been the collection of subpaddock pasture clippings and direct determination of the DM content, the nutrient content, the survival of probiotic populations on the pasture grasses, and the distribution of plant growth stages (e.g., 2 leaf, 3 leaf) of the ryegrass. The measured pregrazing pasture cover was the same for both members of a subpaddock pair. However, it is possible that the nutritional quality of the grazed plants was greater in the GL-treated paddocks. It is also possible that the observed equivalence of the preand postgrazing pasture cover ( $\mathrm{kg}$ of $\mathrm{DM} / \mathrm{ha}$ ) missed significant differences in plant quality because the measurement did not distinguish between the stage of plant growth (leaf stage). Microclimate changes (lodging of plants due to focal wind currents) could have affected the estimates of pasture herbage mass. However, it is unlikely that this would have been an ongoing effect and limited to just 1 of the 2 treatment groups.

Several management factors could have minimized the beneficial effect of the application of GL to pasture. The nutritional value of pasture is dependent on the plant species and cultivar and the stage of growth at which the plant is consumed. Timely rotation of the grazing plots may have maximized the amount of plant herbage in both the GL-treated and untreated subpaddocks, which were at the optimum stage of nutritional value (2 leaf; Gregorini et al., 2014; Wims et al., 2014). Astute grazing management by the producer could have minimized the additional beneficial effect on pasture quality due to the application of GL. If the existing nutritional deficit of the prestudy pasture was small, the marginal milk production response to GL application may have been minimized. The small improvement in pasture due to GL application could have minimized the increase in the milk production response. If this is correct, then application of GL to a pasture with significant deficiencies may result in a potentially greater increase in the production response and a significant economic return. Further studies would be required to test this hypothesis.

\section{CONCLUSIONS}

The cows that grazed pasture treated with GL produced a significantly higher volume of milk and a higher quantity of milk protein. There were tendencies toward production of more milk fat. The application of this probiotic was not associated with either the amount of forage available for grazing on the paddocks or pasture consumption. Further studies should investigate the role of different soil types, pasture plant mixes, grazing patterns, and environmental variation on the effect of pasture application of GL.

\section{ACKNOWLEDGMENTS}

We thank and acknowledge the management and staff of the study farm (Paul Roderick, Michael Sweetman, Leon Zimmerman, Simon Coulet, and Adrienne Jonnet; Southeastern Queensland, Australia), who provided the husbandry and care of the study animals, and Melissa Kane and Nisa Moore (The University of Queensland, School of Veterinary Science, Gatton, Australia), who assisted in the conduct of the study activities. We also thank the reviewers for their insightful comments on this paper. This study was funded by Terragen Biotech Pty Ltd. (Melbourne, VIC, Australia).

\section{REFERENCES}

Bello, N. M., M. Kramer, R. J. Tempelman, W. W. Stroup, N. R. St-Pierre, B. A. Craig, L. J. Young, and E. E. Gbur. 2016. Short communication: On recognizing the proper experimental unit in animal studies in the dairy sciences. J. Dairy Sci. 99:8871-8879.

Chapman, D. F., S. N. Kenny, D. Beca, and I. R. Johnson. 2008. Pasture and forage crop systems for non-irrigated dairy farms in southern Australia. 2. Inter-annual variation in forage supply, and business risk. Agric. Syst. 97:126-138.

Australia, D. 2013. Cow Body Condition Scoring Handbook. Accessed June 1, 2016. https://www.dairyaustralia.com.au/farm/animal -management/fertility/body-condition-scoring?section=cow_body _conditioning_scoring_handbook\#accordion-1.

Diggle, P. J. 2002. Analysis of Longitudinal Data. Oxford University Press, Oxford, UK.

Dillon, P., J. R. Roche, L. Shalloo, and B. Horan. 2005. Optimising financial return from grazing in temperate pastures. Pages 131-147 in Utilisation of Grazed Grass in Temperate Animal Systems: Proc. Satellite Workshop of the XXth International Grassland Congress. J. J. Murphy, ed. Wageningen Academic Publishers, Wageningen, the Netherlands.

Doyle, P. T., and C. R. Stockdale. 2011. Dairy farm management systems: Seasonal, pasture-based, dairy cow breeds. Pages 29-37 in Encyclopaedia of Dairy Sciences. 2nd ed. J. W. Fuquay, P. F. Fox, and P. L. H. McSweeney, ed. Academic Press, Amsterdam, the Netherlands.

Ferris, C. P. 2007. Sustainable pasture based dairy systems-Meeting the challenges. Can. J. Plant Sci. 87:723-738.

Fike, J. H., C. R. Staples, L. E. Sollenberger, B. Macoon, and J. E. Moore. 2003. Pasture forages, supplementation rate, and stocking rate effects on dairy cow performance. J. Dairy Sci. 86:1268-1281.

Gregorini, P., J. Galli, A. J. Romera, G. Levy, K. A. Macdonald, H. H. Fernandez, and P. C. Beukes. 2014. Incorporating a prediction of postgrazing herbage mass into a whole-farm model for pasturebased dairy systems. J. Dairy Sci. 97:4354-4366.

Hanrahan, L., N. McHugh, T. Hennessy, B. Moran, R. Kearney, M. Wallace, and L. Shalloo. 2018. Factors associated with profitability in pasture-based systems of milk production. J. Dairy Sci. 101:5474-5485.

Hopkins, A., and R. J. Wilkins. 2006. Temperate grassland: Key developments in the last century and future perspectives. J. Agric. Sci. 44:503-523.

Macdonald, K. A., G. A. Verkerk, B. S. Thorrold, J. E. Pryce, J. W. Penno, L. R. McNaughton, L. J. Burton, J. A. S. Lancaster, J. H. Williamson, and C. W. Holmes. 2008. A comparison of three 
strains of Holstein-Friesian grazed on pasture and managed under different feed allowances. J. Dairy Sci. 91:1693-1707.

Mulliniks, J. T., A. G. Rius, M. A. Edwards, J. D. Hobbs, and R. L. G. Nave. 2015. Forages and Pastures Symposium: Improving efficiency of production in pasture- and range-based beef and dairy systems. J. Anim. Sci. 93:2609-2615.

Pinheiro, J., D. Bates, S. DebRoy, D. Sarkar, and R Core Team. 2008. nlme: Linear and Nonlinear Mixed Effects Models. R package version 3.1-88. R Foundation for Statistical Computing, Vienna, Austria.

R Development Core Team. 2010. R: A Language and Environment for Statistical Computing. R Foundation for Statistical Computing, Vienna, Austria

Shalloo, L., P. Creighton, and M. O'Donovan. 2011. The economics of reseeding on a dairy farm. Ir. J. Agric. Food Res. 50:113-122.
Stergiadis, S., M. Allen, X. Chen, D. Wills, and T. Yan. 2015. Prediction of nutrient digestibility and energy concentrations in fresh grass using nutrient composition. J. Dairy Sci. 98:3257-3273.

Tempelman, R. J. 2004. Experimental design and statistical methods for classical and bioequivalence hypothesis testing with an application to dairy nutrition studies. J. Anim. Sci. 82(E-Suppl.):E162E172.

Waghorn, G. C., and D. A. Clark. 2004. Feeding value of pastures for ruminants. N. Z. Vet. J. 52:320-331.

Wims, C. M., L. Delaby, T. M. Boland, and M. O'Donovan. 2014. Effect of pre-grazing herbage mass on dairy cow performance, grass dry matter production and output from perennial ryegrass (Lolium perenne L.) pastures. Animal 8:141-151. 